\title{
Why does the effect of new business formation differ across regions?
}

\author{
Michael Fritsch • Alexandra Schroeter
}

Accepted: 23 December 2008/Published online: 22 January 2010

(C) The Author(s) 2010. This article is published with open access at Springerlink.com

\begin{abstract}
We investigate regional differences in the effect of new business formation on employment growth in West Germany. We find an inverse Ushaped relationship between the level of start-up activity and employment change. The main variables that shape the employment effects of new businesses in a region are population density, the share of medium-skilled workers, the amount of innovation activities as measured by the proportion of research and development (R\&D) employees, and an entrepreneurial character of the regional technological regime. In contrast, a high share of small-business employment has a negative influence on the employment effect of start-ups. Other indicators for education, innovation activity, and labor productivity do not prove to be statistically significant.
\end{abstract}

Keywords Entrepreneurship - New business

formation - Regional development .

Entrepreneurship policy

JEL Classifications $\quad \mathrm{L} 26 \cdot \mathrm{M} 13 \cdot \mathrm{O} 1 \cdot \mathrm{O} 18 \cdot \mathrm{R} 11$

M. Fritsch ( $\square) \cdot$ A. Schroeter

School of Economics and Business Administration,

Friedrich Schiller University Jena, Carl-Zeiss-Str. 3, 07743 Jena, Germany

e-mail: m.fritsch@uni-jena.de

A. Schroeter

e-mail: alexandra.schroeter@uni-jena.de

\section{Aims and scope ${ }^{1}$}

Recent empirical research strongly indicates that the effect of new business formation on economic development is of a long-term nature. ${ }^{2}$ It is found that start-up rates may have a statistically significant impact on growth for a period of up to 10 years (for an overview, see Fritsch 2008). Over this time span, the effect of start-ups on growth shows considerable variation that is in most cases (countries or regions) characterized by a wave-like pattern (see Sect. 2 for details). This wave-like pattern reveals that new businesses have a positive impact on economic development in the first 1 or 2 years after formation, but that the effect then declines and, in many cases, becomes negative. In many regions, the effect becomes positive again after about 5 years, and then

\footnotetext{
$\overline{1}$ We are indebted to Oliver Falck (CES-ifo, Munich), Stephan Heblich (MPI, Jena), Antonio Garcia-Tabuenca (University of Alcala, Madrid), and two anonymous referees for their helpful comments on an earlier version of this manuscript. Oliver Falck also provided very valuable advice on econometric issues.

2 Acs and Mueller (2008); Andersson and Noseleit (this issue); Arauzo-Carod et al. (2008); Audretsch and Fritsch (2002); Baptista et al. (2008); Baptista and Preto (this issue); Bosma et al. (this issue); Carree and Thurik (2008); Dejardin (this issue); Fritsch and Mueller (2004, 2006, 2008); Koster (this issue); van Stel and Storey (2004); Mueller et al. (2008); van Stel and Suddle (2008).
} 
becomes insignificant after about another 5 years. Previous analyses also find that the magnitude of the "wave," as well as the total effect of new business formation on growth, is shaped to a considerable degree by regional conditions. Some regions are able to achieve substantial employment growth from new business formation; however, the effect can even be negative in other regions (Fritsch 2008).

In this paper, we analyze differences in the total effect of new business formation on regional development in West Germany. Unlike other work on this subject (Fritsch and Mueller 2004, 2008), we are not interested in the 10-year wave pattern as it occurs, but in the overall result after this process has ended. To what extent and why do the long-term effects of new business formation vary between regions? What characterizes those regions where new business formation leads to pronounced employment growth as compared with those regions where this effect is negligible, if it even occurs at all? What is behind these interregional differences? To answer these questions, we employ a panel approach in which we relate regional start-up rates and other regional characteristics to regional employment change over 10 -year periods. This analysis allows us to identify the main factors that shape interregional differences in the effects of new business formation on economic development. Previous analyses of regional differences only compare the effects in different types of regions, such as agglomerations and rural areas or regions with high and low levels of productivity; however, our approach allows us to account simultaneously for several factors that may shape these effects, e.g., population density and productivity. ${ }^{3}$

\footnotetext{
${ }^{3}$ E.g., Fritsch and Mueller (2008) find that the effect of new business formation on regional employment is relatively large in agglomerations and in regions with high levels of labor productivity. Since, in West Germany, most of the regions with high labor productivity are agglomerations and many of the low-productivity regions are rural areas (Fritsch and Mueller 2008 , p. 22), a larger growth effect of new business formation in regions with high productivity levels could well be explained by their higher population density. In this paper (Sect. 5), we indeed find that the regional productivity level does not contribute to explaining the effect of new business formation on regional development when population density is included in the analysis.
}

The following section provides an overview of recent empirical research on the regional employment effects of new businesses. We then derive hypotheses about the reasons for regional differences in Sect. 3 . Section 4 introduces the data and the empirical approach. The results of our empirical investigation are presented in Sect. 5. Section 6 concludes.

\section{The effects of new business formation on employment}

New business formation can affect regional development in a variety of ways (for a detailed overview, see Fritsch 2008). The evolution of the newcomers, e.g., as measured by the number of their employees or by their market share (the direct effect of new businesses on employment change), is only a part of the contribution that new businesses make to economic development. Due to competition and market selection, only a fraction of start-ups survive for any appreciable length of time (Boeri and Cramer 1992; Fritsch and Weyh 2006; Schindele and Weyh 2010), and those that do may displace incumbents. Given that market selection is a survival-of-the-fittest scenario, firms with relatively high productivity will remain in the market while those with low productivity either have to reduce their output or exit. ${ }^{4}$ At a constant output level, this market selection process should lead to a decline in employment, instead of a gain, because the more productive survivors will need fewer resources (including labor) to produce a given amount of goods and services. Hence, although starting a new business means creating additional capacities that require personnel for their operation, the process of creative destruction initiated by the new entries does not necessarily result in higher employment; indeed, it could also lead to a decline in employment.

There are, however, several ways in which new business entry can stimulate improvements on the supply side of the regional economy that may, in turn,

\footnotetext{
${ }^{4}$ Crowding-out effects may occur in the output market because the entrants gain market share, as well as in the input market due to the new businesses' demand for resources, resulting in scarcity of inputs and increasing factor prices.
} 
lead to improved competitiveness and higher employment levels. The main supply-side effects of entry include securing efficiency by contesting established market positions, acceleration of structural change, amplified innovation, and greater variety of products and problem solutions (for a more detailed exposition, see Fritsch 2008). These supply-side effects are the reason why one should expect positive employment effects from new business formation. ${ }^{5}$ However, these positive effects will not manifest in the absence of a survival-of-the-fittest market environment. If this condition is not met and the actual market mechanism somehow forces the relatively efficient firms to exit and allows the inefficient firms to survive, economic competitiveness will wane.

Empirical analyses of the employment effect of new business formation show that the effect can be spread over a period of about a decade. Some studies find considerable between-region variation in the overall effect of new business formation on economic development; for example, Fritsch and Mueller (2004, 2008) and van Stel and Suddle (2008) show that the effects are more pronounced and, particularly, more positive in agglomerated areas than they are in rural regions. Fritsch and Mueller (2008) also find that the overall effects of start-ups on employment in high-productivity regions are generally positive but that new business formation can have a negative effect in low-productivity areas. This clearly suggests that, in certain regions, new business formation may lead to a decrease instead of an increase in employment. Negative overall effects of new business formation on employment are also found by Mueller et al. (2008) for Scotland and Wales as well as for those regions of Great Britain that are characterized by a relatively low start-up rate. Van Stel and Suddle (2008) identify an overall negative impact of new business formation in the rural regions of The Netherlands. Acs and Mueller

\footnotetext{
5 The emergence of the supply-side effects of new business formation does not necessarily require the newcomers to be successful and to be able to survive. As long as entry induces improvements on the side of the incumbents, it will generate positive supply-side effects, even if most of the new businesses fail and have to exit the market shortly after entry. Therefore, even failed start-ups may also make a significant contribution to the improvement of competitiveness.
}

(2008) compare effects between metropolitan statistical areas (MSAs) in the USA which have a relatively high share of rapidly growing companies ("gazelles") and the rest of the regions of their sample and find that the start-ups in the gazelle regions produce larger employment effects.

According to the above results, it is not at all obvious that new business formation will have a positive impact on regional economic development. Sometimes it does; sometimes it does not. That much, at least, is clear. What is not so clear is what causes this variation, which is our next avenue of exploration.

\section{What determines the magnitude of the regional employment effects?}

The above theories and explanations as to how new business formation affects regional development give rise to the idea that a considerable part of any growth is due to the challenge that the new businesses pose to incumbents. This challenge and incumbent firms' reaction to it can be seen as one of the key determinants of the supply-side effects of new business formation. By extension, then, we may expect that, the greater this challenge, the larger the overall effects initiated by the establishment of a start-up. Hence, the extent to which the quality of the new business poses a challenge to incumbents should be an important factor. Quality can manifest in many dimensions, of course, including the innovativeness of goods and services, the efficiency of production, the entrepreneur's qualifications, the amount and quality of resources available to the venture, and even the marketing strategy pursued. Hence, it does not take a very big leap of the imagination to think that a well-prepared innovative entry poses a much stronger challenge to incumbents, and therefore has the potential to have a considerably larger impact on overall employment, than a purely imitative start-up run by an unqualified person unable to acquire sufficient capital or appropriate personnel.

The innovativeness of regional entries, which constitutes one important aspect of their quality as explained above, may critically depend on the characteristics of the regional environment, such as the availability of important resources (e.g., venture capital, supportive services, qualified labor), the 
regional knowledge base (innovation activity of regional firms, presence and quality of universities and other public research institutes), and the intensity of the regional knowledge spillovers. As the incumbent firms in the respective region also benefit from these factors, their presence does not necessarily lead to higher survival chances of newcomers and higher direct employment effects. However, high-quality entry and a high-quality response from the incumbent should produce relatively pronounced supply-side improvements that result in correspondingly high employment growth.

A number of these possible determinants of highquality start-ups should be more pronounced in agglomerations than in other regions, particularly remote rural areas. For example, agglomerations are often characterized by a large supply of qualified labor and other inputs, they tend to have a rich knowledge base due to being home to universities and other kinds of research institutions, and the chance of knowledge spillovers is greater due to a higher number of innovative actors (for an overview, see Schroeter 2009). Empirical research clearly supports these suppositions; for example, it has been found that the share of qualified labor, measured as employees with a university degree, is relatively high in agglomerations (Glaeser 1999; Florida 2005). Also, the number and share of startups in knowledge-intensive and in high-technology industries tends to be relatively high in agglomerations (Audretsch et al. 2006, pp. 87-90; Bade and Nerlinger 2000; Schroeter 2009 ). ${ }^{6}$ This larger share of high-quality entry should also contribute to a high intensity of competition and market selection in agglomerations, leading to relatively large employment effects of new business formation processes.

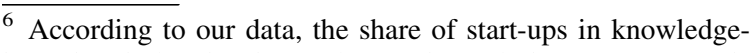
intensive industries in agglomerations during 1998-2002 is $33.6 \%$ as compared with $28.4 \%$ in rural regions and $30.0 \%$ in the intermediate category of moderately congested regions. The share of start-ups in high-technology industries in all manufacturing start-ups is $11.9 \%$ in agglomerations, $9.7 \%$ in moderately congested regions, and $10.0 \%$ in rural regions. [For the classification of German industries, see Grupp and Legler (2000).] Unfortunately, our database allows only a rather crude identification of knowledge-intensive and high-technology industries in the years prior to 1998.
}

Another important feature of agglomerations is that their high density of economic activity results in a correspondingly high degree of competition, i.e., more firms demanding similar inputs from or supplying goods and services to the same market. This high level of competition may facilitate the process of market selection and stimulate the performance of the surviving firms. ${ }^{7}$ Hence, high-density areas should be characterized by a relatively high level of competitiveness due to high entry rates and rigorous market selection.

Regions in which most of the incumbent businesses are characterized by a relatively high productivity level can be expected to experience a less severe decline in employment due to the displacement effects of entry as compared with regions where a high share of the suppliers fall in the low productivity range. Moreover, incumbent firms operating close to the efficiency frontier may be better able to react to the need for improvements, thereby generating stronger supply-side effects if challenged by entries compared with the performance of lowproductivity suppliers (Aghion et al. 2009). It thus may be expected that the supply-side effects in highproductivity regions will be more significant than they are in regions with a relatively low level of productivity.

Prosperous economic conditions in a region, as reflected by a strong rise in demand and a low unemployment rate, may be especially conducive to the survival of new businesses and to pronounced direct employment effects. However, a prosperous environment can also result in a scarcity of resources and high factor prices, which impede the development of start-ups.

A region with a high share of small businesses may imply a favorable environment for start-ups, particularly with regard to the availability of inputs, as compared with a region dominated by large firms that tend to pay higher wages and provide better career opportunities for their personnel (Brixy et al. 2007). However, the small-firm sector may comprise a relatively high share of suppliers which are less

\footnotetext{
7 This conjecture regarding the relatively high level of competition in agglomerations is supported by empirical analyses that find a higher level of start-ups (Brixy and Niese 2006; Fritsch and Falck 2007), but a lower probability of survival (Fritsch et al. 2006; Weyh 2006), in these areas.
} 
competitive than larger firms, so that supply-side effects in regions with high shares of small-firm employment may be relatively small. Contestability of market position and survival probability may also be shaped by the type of technological regime that prevails in the industry and region (Audretsch 1995, pp. 39-64; Winter 1984). In an entrepreneurial regime where small firms play an important role in innovation processes, it should be easier for newcomers to mount a serious challenge to incumbents than it would be in a routinized regime where large firms have the innovative advantage. Accordingly, new business formation can be expected to be an important determinant of growth in an entrepreneurial industry or region but to a much lesser degree in an industry or region that is routinized. Although the theory of technological regimes was originally developed for industries, it is also applicable to geographical units of observation (Audretsch and Fritsch 2002; Fritsch and Mueller 2006). Empirical research shows that an industry's mode of production in a particular location may be specific and distinct from the type of production found in other regions. ${ }^{8}$ This implies that the technological regime of an industry is not necessarily invariant over space, but that there may be important differences that can lead to divergent regional performance.

The above discussion makes it clear that the effects of new business formation will not be identical in all regions; indeed, considerable variation across space should be the norm. The employment effects of new business formation will probably be larger in high-density regions that have a high level of productivity and a large share of high-quality entries, abundant resources, and a well-functioning innovation system. They will be much smaller or even negative in low-productivity regions that have a high share of low-quality entries, a scarcity of relevant resources, and a routinized technological regime.

It would be unrealistic to expect the marginal effect of entry on regional growth to be of about the same magnitude at all levels of new business formation activity; rather, the marginal effect of additional start-ups should decrease. One cause for

\footnotetext{
${ }^{8}$ Saxenian's (1994) study of the US computer industry in both the Boston area and Silicon Valley provides an illustrative example of such different regional regimes in an industry.
}

decreasing marginal effects of new business formation could be a declining average quality of start-ups that will occur if high-quality business ideas have a relatively high probability of being realized and if the potential number of high-quality start-ups in a region is limited. Another reason could be the increasing cost of creative destruction caused by the reallocation of resources initiated by newcomers.

\section{Data and empirical approach}

\subsection{Data}

Our analysis of the effect of new business formation on regional economic development over time is at the spatial level of planning regions (Raumordnungsregionen). Planning regions are comprised of at least one core city and the surrounding area. The advantage of using planning regions, as compared with districts (Kreise), is that they can be regarded as functional units in the sense of traveling-to-work areas and that they account for economic interactions between districts. Planning regions are slightly larger than what is usually defined as a labor market area. A district, on the other hand, may be comprised of a single core city or a part of the surrounding suburban area (for the definition of planning regions and districts, see Federal Office for Building and Regional Planning 2003). We restrict the analysis to the planning regions of West Germany and exclude East Germany, for two reasons. First, the time series of available data for East Germany is much shorter than for West Germany, beginning in the year 1993. Second, many analyses show that developments in East Germany in the 1990s were heavily shaped by its transition to a market economy and, therefore, it is a rather special case that should be analyzed separately (e.g., Kronthaler 2005). It was also necessary to exclude the Berlin region from our analysis due to changes in the definition of that region after the unification of Germany in $1990 .^{9}$ Moreover, start-ups

\footnotetext{
${ }^{9}$ For historical reasons, the cities of Hamburg and Bremen are defined as planning regions even though they are not functional economic units. To avoid possible distortions, we merged these cities with adjacent planning regions (Hamburg with the region of Schleswig-Holstein South and Bremen with BremenUmland). Therefore, we have 71 regions in our sample.
} 
and employment in agriculture and fishery, energy, mining, railways, and postal services are excluded because of the highly regulated market conditions in these industries.

The data used in this study stem from the Establishment History Panel, which is based on official employment statistics and comprise information on all establishments that have at least one employee subject to obligatory social insurance (see Spengler 2008, for a description). Start-ups in which the owner is the only actor are not included. In order to avoid distortions caused by new large subsidiary plants of incumbent firms, new establishments with more than 20 employees in the first year of their existence are not counted as start-ups. ${ }^{10}$ Other data are taken from various publications of the German Federal Statistical Office.

New business formation activity is measured by the yearly start-up rates calculated according to the labor market approach; namely, the number of startups per period is divided by the number of persons in the regional workforce (in thousands) at the beginning of the respective period. An important adjustment was made to control for the fact that not only does the composition of industries vary considerably across regions, but the relative importance of startups and incumbent enterprises also varies systematically across industries. For example, start-up rates are higher in the service sector than in manufacturing industries. This means that the relative importance of start-ups and incumbents in a region is confounded by the composition of industries in that region. This would result in overestimation of the level of entrepreneurship in regions that are home to a large number of industries for which start-ups play an important role, and underestimation of the role of new business formation in regions that are home to a high share of industries characterized by relatively low start-up rates. To correct for the confounding effect of the regional composition of industries on the number of start-ups, a shift-share procedure was employed to obtain a sector-adjusted measure of start-up activity (for details, see Audretsch and Fritsch 2002, Appendix). This sector-adjusted number of start-ups is defined as the number of new businesses in a region that could be expected if the

\footnotetext{
10 The share of new establishments in the data with more than 20 employees in the first year is rather small, about $2.5 \%$.
}

composition of industries were identical across all regions. Thus, the measure adjusts the raw data by imposing the same composition of industries upon each region. Our analysis shows that this procedure leads to somewhat clearer results and higher levels of determination than the estimates using the nonadjusted start-up rate. However, the basic relationships are left unchanged. Table 3 in the Appendix provides descriptive statistics for the variables used in the analysis.

According to our data, on average 107,356 new businesses were founded every year during the 19802002 period. The majority of the start-ups $(76.5 \%)$ were in the service sector, whereas $20.9 \%$ and $2.6 \%$ occurred in manufacturing and other industries, ${ }^{11}$ respectively. Most new businesses were set up in agglomerations (57.6\%); only $10.6 \%$ were located in rural regions. The start-up rate was calculated according to the labor market approach as the number of new businesses per year divided by the number of employees (per 1,000) in the respective sector at the beginning of the respective period. ${ }^{12}$ There were about 8.74 new businesses per 1,000 employees in West Germany during the period 1980-2002.

\subsection{Empirical approach}

To identify and analyze regional differences in the employment effects of new business formation, we employ a robust fixed-effects estimator. Our indicator of regional development is the average employment change (percentage) over a 2-year period. A 2-year average is used in order to avoid disturbances caused by short-term fluctuations. The regional differences

\footnotetext{
11 The "other industries" comprise agriculture, forestry, and fishery (SIC codes 01-09); energy and water supply (SIC code 49); mining (SIC codes 19-14); and construction (SIC codes 15-17).

${ }^{12}$ Unemployed members of the workforce were not accounted for because unemployment cannot be assigned to sectors. This kind of start-up rate is based on the notion that each member of the workforce chooses between working in someone else's business or starting his or her own firm. As start-ups are usually located close to the founder's residence (Mueller and Morgan 1962; Stam 2007), size of the regional workforce is an appropriate measure of the number of potential entrepreneurs. According to the labor market approach, the entry rate may be interpreted as the propensity of a member of the regional workforce to start his or her own business.
} 
of the effects of start-up activity on employment change are estimated by the regression:

$$
\begin{aligned}
& \text { Average employment change } r \text {, to } t+2 \\
& =a+b_{1} \times \text { average start }- \text { up rate } \text { rr,t }-1_{\text {to } t-10} \\
& +b_{2} \times \text { average start }- \text { up rate }{ }_{r, t-1}^{2} \text { to } t-10
\end{aligned}
$$

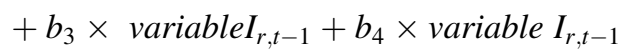

$$
\begin{aligned}
& \times \text { average start }- \text { up rate } r, t-1 \text { to } t-10 \\
& +b_{5} \times \text { variable } I I_{r, t-1}+b_{6} \times \text { variable } I I_{r, t-1} \\
& \times \text { average start }- \text { up rate } \text { r,t }-1_{\text {to } t-10} \\
& + \text { industry shares }{ }_{r, t-1}+\text { time dummies }+u_{r, t},
\end{aligned}
$$

where $r$ indicates the regions and $t$ time. The average start-up rate is calculated as a mean over a period of 10 years from $t-10$ to $t-1$. A period of 10 years is used in order to account for the relevant long-term effects that have been found in recent analyses (Fritsch 2008). We also include the squared value of the start-up rate to account for a nonlinear relationship with employment change. If the marginal effect of new business formation on regional employment is declining with the number of start-ups, the coefficient for the average start-up rate should be positive, whereas the coefficient for its squared value should be negative. Several further variables that may determine regional growth and that could also be responsible for differences in the employment effects of start-ups such as population density, the qualification of the workforce, labor productivity, and the regional level of innovation activity (see Sect. 4.3) are included, as are the interactions of these variables with the start-up rate. All independent variables are lagged by 1 year.

The estimated coefficients of the start-up rates and of the potential growth determinants indicate their direct influence on employment change. The coefficients of the interaction terms can be regarded as a measure of the impact that the respective variable has on the employment effect of the new businesses. This makes it possible to distinguish between the direct effects of several regional characteristics and the impact that these potential determinants of regional growth may have through new business formation activity. As an example, note that in our data employment in agglomerations grew less than in the other types of regions during the period under inspection. Therefore, the coefficient for population density should be negative. However, a number of studies on the employment effects of new businesses find that the employment gain due to start-ups is higher in agglomerations than in other areas (Sect. 3). This effect is measured by the interaction of the startup rate with population density. If new businesses in agglomerations do, indeed, have a larger positive impact on regional employment, the coefficient for this interaction variable should be positive (see Brambor et al. 2005).

In order to account for the influence of industry structure on employment growth (Glaeser et al. 1992; Peneder 2002; Combes 2000), we also included the employment shares of 27 out of 28 aggregated private industries into our model. Year dummies control for special influences of certain years as well as for time trends. Since local employment growth may also be driven by geographic proximity to other markets, we included a Harris-type market potential function, which is a distance-weighted sum of total employment in all other regions (Redding and Sturm 2008, Südekum 2008) that shall also control for spatial autocorrelation.

Models with interaction terms should always also include the respective variables in their noninteracted form. The regression coefficients for the noninteracted variables can, however, not be interpreted directly. The reason is that these coefficients do not represent the unconditional or average effect of the respective variable but the result of a one-unit change in the independent variable on the dependent variable if the value of the conditioning variable (in our case the variables indicating the potential determinants of growth) assumes a zero value. However, if the conditioning variable does not have the value of zero, the coefficients need to be calculated for the relevant values (Brambor et al. 2005). For our model with the start-up rate, the squared value of the start-up rate and a further variable, the marginal effect of new business formation on employment change is:

$$
\begin{aligned}
& \frac{\text { Average employment change } e_{r, t o t+2}}{\text { average start }- \text { up rate }_{r, t-1} \text { to } t-10} \\
& \quad=b_{1} \times \text { average start }- \text { up rate } r, t-1 \text { to } t-10 \\
& \quad+2 \times b_{2} \times \text { average start }- \text { up rate } \text { r }_{r, t-1} \text { to } t-10 \\
& \quad+b_{4} \times \text { variable }_{r, t-1} .
\end{aligned}
$$

For continuous variables, marginal effects are difficult to discern in table format; figures are much better suited for illustrating the marginal effect of the independent variable across a substantively meaningful range of values. 
Table 1 Definition of the variables and expected signs for their interaction terms with new business formation

\begin{tabular}{|c|c|c|}
\hline Variable & Definition & Expected sign \\
\hline Start-up rate & Number of start-ups in a region over the regional workforce ${ }^{\mathrm{a}}$ & + \\
\hline Population density & Number of inhabitants in a region per square kilometer $(\log )^{c}$ & + \\
\hline High education level & Share of employees in a region with a university degree ${ }^{a}$ & + \\
\hline Medium education level & $\begin{array}{l}\text { Share of employees with secondary degree and/or vocational } \\
\text { training (skilled labor) }{ }^{\mathrm{a}}\end{array}$ & + \\
\hline R\&D employees & $\begin{array}{l}\text { Share of employees with tertiary degree working as engineers or } \\
\text { natural scientists }\end{array}$ & + \\
\hline Unemployment rate & Share of unemployed persons in the regional workforce ${ }^{b}$ & \pm \\
\hline Short-term unemployment rate & $\begin{array}{l}\text { Share of persons in the regional workforce who have been } \\
\text { unemployed for up to one year }\end{array}$ & \pm \\
\hline Long-term unemployment rate & $\begin{array}{l}\text { Share of persons in the regional workforce who have been } \\
\text { unemployed for more than } 1 \text { year }\end{array}$ & - \\
\hline Labor productivity & Gross value added $^{\mathrm{c}}$ per employee ${ }^{\mathrm{a}}$ in a region & + \\
\hline Small-business presence & $\begin{array}{l}\text { Share of employees in small-sized private-sector businesses }(<50 \\
\text { employees) in a region }{ }^{\mathrm{a}}\end{array}$ & \pm \\
\hline Entrepreneurial technological regime & $\begin{array}{l}\text { Share of } R \& D \text { employees in establishments with fewer than } 50 \\
\text { employees over the share of } R \& D \text { employment in total } \\
\text { employment in the respective region, industry, and year }\end{array}$ & + \\
\hline
\end{tabular}

${ }^{\mathrm{a}}$ Source: Social Insurance Statistics; ${ }^{\mathrm{b}}$ Federal Employment Services; ${ }^{\mathrm{c}}$ Federal Statistical Office

4.3 Further determinants of regional growth and employment effects

We tested the following variables, any or all of which may be responsible for regional growth and the effect new business formation has on employment change (cf. Table 1).

Population density indicates the advantages as well as the disadvantages of being located in an agglomeration. Among the chief advantages (agglomeration economies) are the availability of large, differentiated labor markets and specialized services, proximity to research institutions, large demand, and a high level of regional knowledge spillover (see Duranton and Puga 2004 for an overview on agglomeration economies). The main disadvantages of agglomerations (agglomeration diseconomies) include the higher cost of resources such as labor and floor space, more intense local competition, and a variety of congestion-related problems (Glaeser 1998). There is a considerable degree of correlation between population density and a number of other regional characteristics, such as qualification of the workforce, regional income level, and labor productivity. Population density can, therefore, be viewed as a sort of "catch-all" local conditions variable. However, recent empirical studies suggest a negative employment development trend in German agglomerations (Kowalewski and Niebuhr 2008). Hence, we expect a negative growth impact of density. Opposed to that, Fritsch and Mueller (2004, 2008) as well as van Stel and Suddle (2008) found much more pronounced employment effects of startups in agglomerations than in moderately congested or rural regions. We therefore assume a positive effect of density on the employment effects of new business formation. Since the qualification of the workforce is one of the basic determinants of economic growth (Lucas 1988), we suggest that the regional share of highly and medium-skilled workers has a positive influence on employment growth. ${ }^{13}$ Concerning the employment effects of start-ups, the qualification level of the regional workforce may also be relevant in several aspects. First, assuming that new businesses are set up by members of the regional

\footnotetext{
$\overline{13}$ A positive growth effect of human capital has been confirmed in several studies, particularly for the USA, showing a robust positive correlation between the initial employment share of college-educated workforce and subsequent total employment growth in MSAs. See Glaeser et al. (1995); Simon and Nardinelli (2002) as well as Shapiro (2006) for the USA, and Südekum (2008) for Germany.
} 
workforce, ${ }^{14}$ the share of highly qualified workforce may imply a large share of high-quality start-ups, which in turn exert strong pressure on incumbents. Second, workforce quality can be seen as a measure of the availability of certain qualifications in a region that may be important to the success of new businesses. Third, regional workforce qualifications can be a reflection of the human capital employed in incumbent firms and provide a clue as to how these firms will react to the challenge of a new entrant, thus influencing, albeit indirectly, the effects of new business formation. We thus expect a positive relationship between this variable and the employment effects of new businesses. We test two measures of regional workforce qualification: the share of employees with a tertiary degree and the share of employees with a medium level of qualification (skilled labor). ${ }^{15}$

The regional share of $R \& D$ employees provides an indicator of the regional efforts in knowledge creation and exploitation, which are the main drivers of technological change and hence regional economic growth (Romer 1986, 1990). Therefore, we expect regions with higher shares of $R \& D$ employees to grow faster than other regions. Moreover, the regional endowment with $\mathrm{R} \& \mathrm{D}$ employees might have an impact on the employment effects of startups in two ways. First, since new knowledge that is created but left unexploited by established firms and organizations is a major source of innovative entrepreneurial opportunities (Audretsch 1995; Acs and Plummer 2005; Audretsch et al. 2006), high R\&D intensity in a region may lead to a respective large share of high-quality or innovative entrepreneurship. As the innovativeness of new businesses reflects the challenge they impose on incumbents to implement improvements in order to stay competitive, highquality start-ups are likely to induce larger employment effects, particularly larger supply-side effects, than are other new ventures (Baptista et al. 2008;

\footnotetext{
14 Empirical analyses (Mueller and Morgan 1962; Cooper and Dunckelberg 1987; Stam 2007) provide clear evidence that the majority of new businesses are set up near to the founder's residence.

15 Included in the medium qualification level are all employees who have vocational training or a high-school diploma but no university degree.
}

Baptista and Preto this issue; van Stel and Suddle 2008; Falck 2007; Engel and Metzger 2006). Second, a high share of R\&D employment may also indicate a high ability of the incumbents to react to the challenges of start-ups in innovative ways, resulting in relatively pronounced improvements on the supply-side of the regional economy.

The regional unemployment rate serves as an indicator of the region's general economic conditions and is obviously negatively related to employment growth. In addition, it can influence the propensity to start a new business as well as its effects. First, a high share of unemployed persons may indicate low levels of local demand and unfavorable conditions for those start-ups that produce mainly for the local market. Second, high unemployment may stimulate new business formation by unemployed persons. Third, high unemployment implies readily available and relatively cheap labor. As these three possible effects of unemployment on start-ups work in different directions, it is unclear a priori what the net effect will be. We distinguish between short-term (up to 1 year) and long-term (more than 1 year) unemployment, expecting a positive influence of short-term unemployment on the effects of start-ups and a negative impact of long-term unemployment. The idea behind this conjecture is that the share of persons who are unemployed for less than 1 year does not necessarily imply an unfavorable economic environment but may be a reflection of regular labor market dynamics. We also expect that persons who have been unemployed for a short time are more likely to start their own business than those who have been out of work for a longer time period, possibly due to the latter suffering human capital ramifications, which would also affect their intent and capability to start a business.

Regional labor productivity indicates a region's competitiveness and is measured as gross value added per employee. There is a pronounced positive relationship between this variable and the level of wages and income. We assume that high regional labor productivity and competitiveness, respectively, should also lead to relatively larger employment growth (Shapiro 2006). As explained in Sect. 3, we expect that high labor productivity in a region will be conducive to the employment effects of start-ups due to lower displacement and stronger supply-side effects.

Small-firm presence is defined as the share of employees in establishments having fewer than 50 
employees. We expect that a regional environment in which small businesses play a considerable role may be more favorable for survival and growth of startups than a regional economy with a high employment share of large establishments, which may particularly dominate the regional factor markets. However, if larger firms tend to be more competitive than smaller firms, regions with high shares of large-firm employment may experience more pronounced supply-side effects. Hence, the overall influence of small-firm presence on the effects of entries is a priori unclear.

The prevalent technological regime is used to discern the importance of small establishments to a region's R\&D activity (Audretsch 1995; Winter 1984). It is measured by the proportion of $R \& D$ employees in establishments with fewer than 50 employees over the share of R\&D employees in total employment. ${ }^{16}$ A technological regime is called "entrepreneurial" if a high share of innovation activity is conducted by small firms; in this environment, entrants have a relatively good chance to compete successfully. In a "routinized" regime, the incumbent large firms have the innovative advantage, thus reducing the survival probabilities of smaller firms.

\section{Results}

In a first step of the analysis, we estimate the effect of new business formation on regional employment change without accounting for other variables that may shape this relationship (model I in Table 2). We find a statistically highly significant positive coefficient for the average start-up rate and a strongly significant negative coefficient for the squared term, indicating an inverse U-shaped relationship. This means that the effect of new business formation on employment change is at first positive with decreasing marginal effects and then, after a maximum is attained, it decreases. The pattern implies that there are decreasing marginal returns for a policy that attempts to boost the regional level of start-up activity in an effort to stimulate employment and that the

\footnotetext{
16 Acs and Audretsch (1987) introduce an output-oriented measure for the technological regime. In their approach, it is the number of innovations per employee introduced by small firms (with fewer than 500 employees) as compared with the number of innovations per employee in all firms.
}

effect of an increasing start-up rate on employment could even be negative in regions where the level of new business formation is already rather high. ${ }^{17}$ The negative sign for the constant term indicates that, without any new business formation, regional employment change would have been negative.

Including population density in our model reveals a negative direct impact on employment change but a positive effect of the interaction with the start-up rate (model II). The negative effect of population density as such indicates below-average employment growth in agglomerations. According to the positive coefficient of the interaction term, the effect of start-ups on employment increases with regional density. This confirms the results of Fritsch and Mueller (2004, 2008) and van Stel and Suddle (2008), who find that the effects of new business formation are more pronounced in agglomerations than in moderately congested or rural regions. Since population density has a rather dominating effect, this variable is always included in the further analysis. According to our expectations, a region's share of highly qualified employees exerts a strongly positive influence on regional employment growth (model III in Table 2). Surprisingly, it has no significant impact on the employment effect of start-ups, which is perhaps a result of the pronounced correlation between this indicator and population density. However, there is a significant direct and indirect effect for the share of employees with a medium education level (model IV), indicating the importance of medium-skilled workforce for employment growth, particularly for growth of new businesses. In Germany, medium-skilled workers tend to possess completed apprenticeships, postsecondary education, and considerable on-the-job experience. Their regional availability might, therefore, be particularly important for the success and growth of start-ups, which typically seldom employ personnel with an academic degree. The regional share of $R \& D$ employees exerts a positive effect on employment creation by new businesses (model V). This supports our conjecture that innovation activity may foster the emergence of high-quality start-ups and that high levels of R\&D can also stimulate innovative

\footnotetext{
17 This inverse U-shaped pattern does not result from observations with relatively extreme values. The respective coefficients remain quite stable when such outlier regions are removed from the sample.
} 


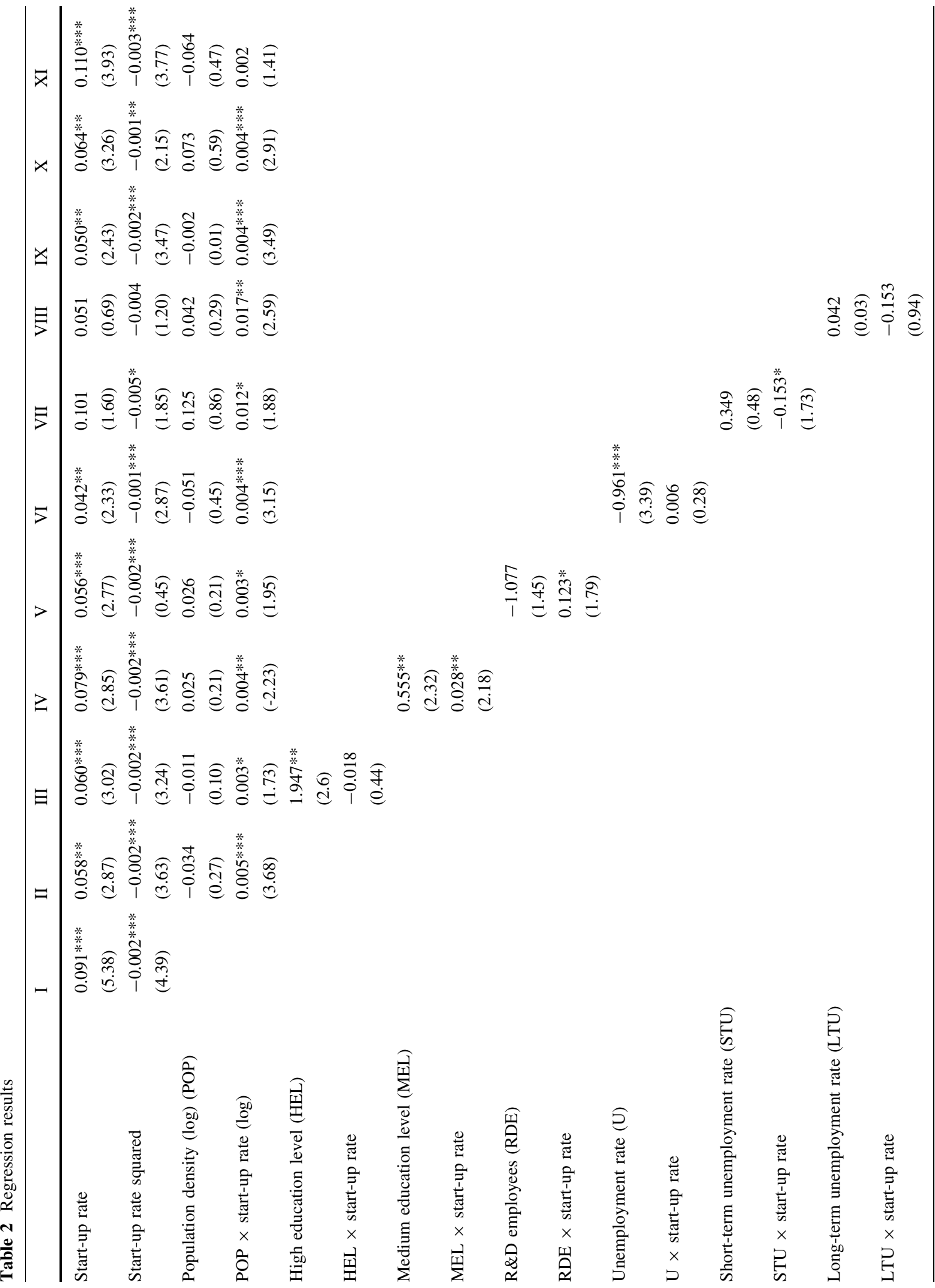




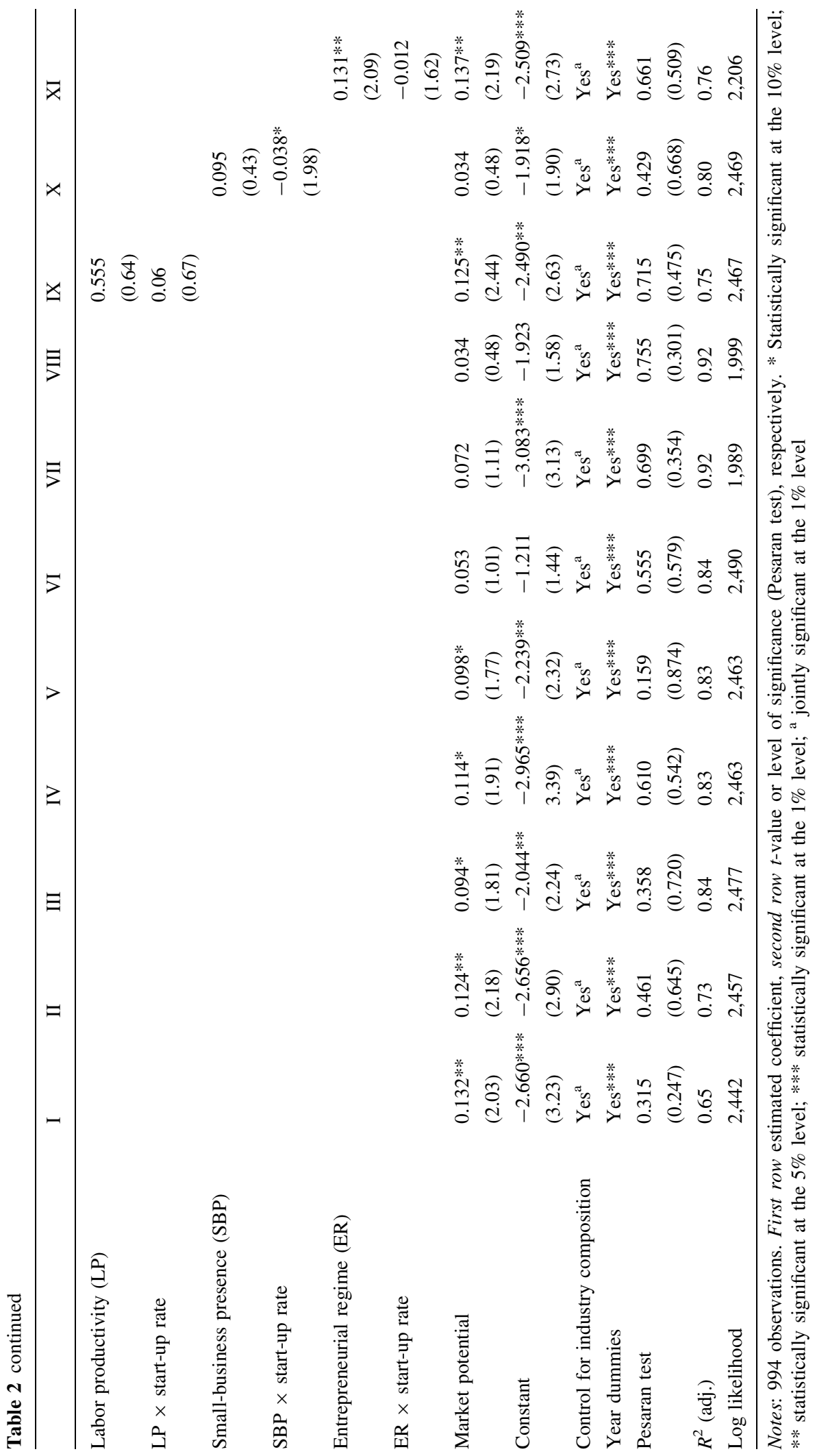


responses of the incumbents to the challenges that are exerted by the newcomers.

Since a high level of unemployment is related to relatively poor employment performance of a region, the negative coefficient for the direct effects of the unemployment rate in model VI is hardly surprising. Distinguishing between short-term and long-term unemployment (model VI and VII), we find that a high level of short-term unemployment seems to negatively influence the employment effects of startups while the coefficients for the long-term unemployment rate remain insignificant.

According to our estimation results, regional labor productivity has neither a statistically significant direct nor an indirect effect caused by new businesses on employment change (model IX). A significantly negative coefficient is found for the interaction of the start-up rate with the indicator of small-business presence (model $\mathrm{X}$ ), suggesting that regions with relatively high shares of small-firm employment tend to draw lower employment growth from new business formation than regions with a high employment share in larger firms. While the measure of the entrepreneurial character of the regional technological regime indicates a positive direct effect on employment change, the coefficient for the interaction term remains insignificant. The statistically positive coefficient for the market potential variable indicates that spatial proximity to a large number of inhabitants (=potential customers) is conducive for regional employment growth. A test for cross-sectional dependence (Pesaran 2004) did not indicate any significant remaining spatial autocorrelation in our models.

Models with more than two additional variables other than the start-up rate did not lead to meaningful results, which may be caused by severe multicollinearity problems since these models contain the startup rate more than four times. Several other variables proved not to be statistically significant, including the presence of academic and nonacademic research institutions, the number of patents per employee, and the regional share of workforce in occupations classified as "creative" (Florida 2005).

To shed more light on the two main findings of the regression analysis-the decreasing employment impacts of start-up rates and the dominating effect of population density-we calculate the marginal effects of these variables on the employment change that is induced by the start-ups. The marginal effects, which are based on the regressions reported in Table 2, allow us to determine the impact of startups on employment at different levels of the start-up rate and various degrees of population density.

Figure 1 shows the employment effects of new businesses dependent on the level of the start-up rate. The dashed lines represent the upper and lower bound of the $95 \%$ confidence interval. The effect of the startup rate on employment change is significant at the 5\% level whenever the upper and lower bounds of the confidence interval are both above (or below) the zero line. Figure 1 demonstrates that the significantly positive employment effects of new businesses decline when the start-up rate increases and even become negative when the average start-up rate exceeds a value of 17 , which is the case for only one out of the 71 regions in our sample. ${ }^{18}$ This means that start-ups have a relatively strong positive impact on employment in regions with low levels of new business formation activity and that the marginal returns of new business formation in terms of additional employment decrease with rising start-up rates. If new business formation activity exceeds a certain level, it will have a significantly negative effect, leading to a decrease in employment. Thus, efforts to stimulate new business formation above a certain level are counterproductive, at least as far as employment levels are concerned. This finding accords with the notion that there is an optimum "equilibrium" number of businesses in a certain industry or region at a particular stage of development (Audretsch et al. 2002; Carree et al. 2007) and that exceeding this equilibrium may hamper economic growth.

Figure 2 displays the marginal effect of start-up rate on employment change dependent on the degree of agglomeration. The marginal impact of new business formation strongly increases with population density, indicating the highest employment effect on start-ups in agglomerations. This finding confirms the results of Fritsch and Mueller $(2004,2008)$ as well as those of van Stel and Suddle (2008), who found that the employment effects of new businesses are considerably more pronounced in agglomerations than in regions with lower population density.

\footnotetext{
${ }_{18}$ The respective region is the Oberland planning region, south of Munich. Many of the start-ups recorded in this region may be relocations out of the prospering Munich region.
} 


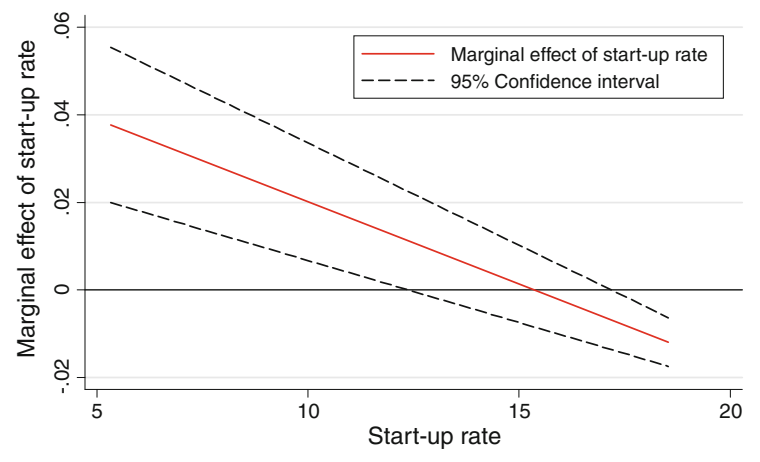

Fig. 1 Marginal effect of start-up rate on employment change in West German regions

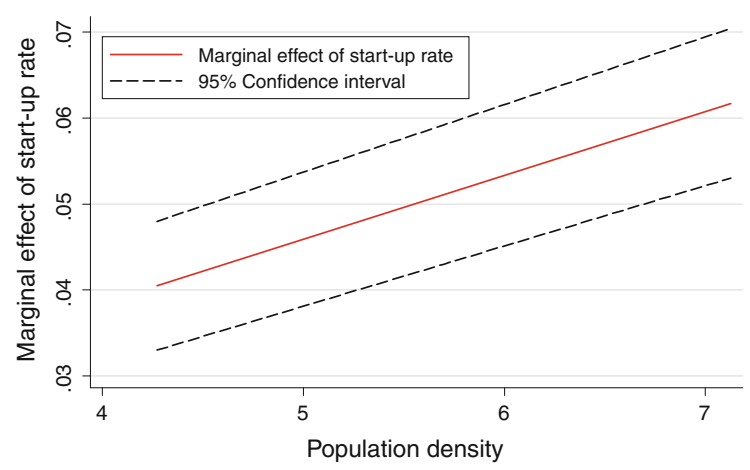

Fig. 2 Marginal effect of start-up rate on employment change in West German regions as the population density changes

\section{Conclusions}

We could show that the effect of new business formation on employment varies considerably between regions. Generally, the positive effect of new business formation becomes smaller with an increasing start-up rate, indicating decreasing marginal returns for a policy aimed at stimulating regional start-up activity. This suggests that regions with a relatively low level of start-ups may benefit more from an increase in the start-up rate than regions in which the start-up rate is already rather high. Our analysis clearly shows that the positive effects of new business formation on employment growth are more pronounced in high-density areas than in rural regions. Moreover, regions with a large share of medium-skilled workers and a high level of innovative activity benefit significantly more from new business formation than do other regions. Although the total unemployment rate seems to be unimportant, a high share of short-term unemployed has a negative influence on the employment effect of start-ups. Moreover, the growth impact of new businesses turns out to be negatively related to the employment share in small establishments. The regional share of highly skilled employees, labor productivity, as well as the entrepreneurial character of the technological regime are insignificant factors when it comes to the employment growth effects of new business formation.

We offer the general conclusion that start-ups tend to make a positive contribution to regional employment, but that the size of the effect may vary considerably depending on regional characteristics, the most significant of which is population density. This implies that policies aimed at stimulating new business formation with the hoped-for result of employment growth will be most effective in highdensity areas with a relatively low start-up rate, a high share of medium-level skills, a high share of innovation activity, and an entrepreneurial character of the regional technological regime. The same policy will be relatively ineffective, and possibly even harmful to employment growth, in rural areas with high start-up rates.

Given the limited number of regions in our sample, some caution is necessary when interpreting the results. We have made a good start at identifying some of the key variables that govern the effects of small-business formation on employment, but other approaches, particularly regional case studies, are necessary for a thorough exploration of the effects. For example, we were able to control for the effect of start-up quality only rather indirectly by using indicators such as qualification level of the regional workforce which turned out to be statistically significant. Better, more direct indicators of start-up quality, when or if such become available, could increase confidence in the findings reported herein and result in better quality and more direct policy-making.

Open Access This article is distributed under the terms of the Creative Commons Attribution Noncommercial License which permits any noncommercial use, distribution, and reproduction in any medium, provided the original author(s) and source are credited.

\section{Appendix}

See Tables 3 and 4. 


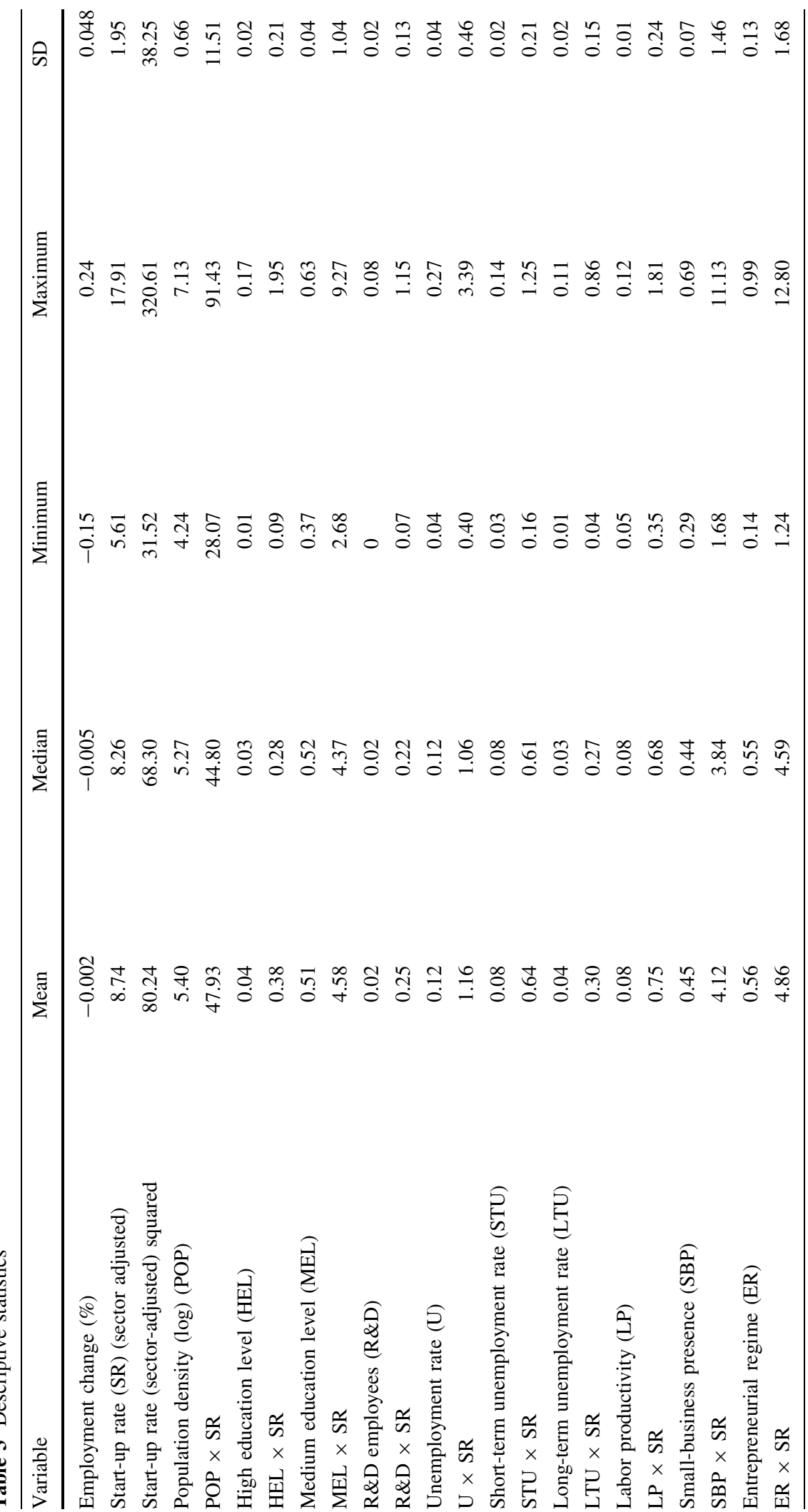




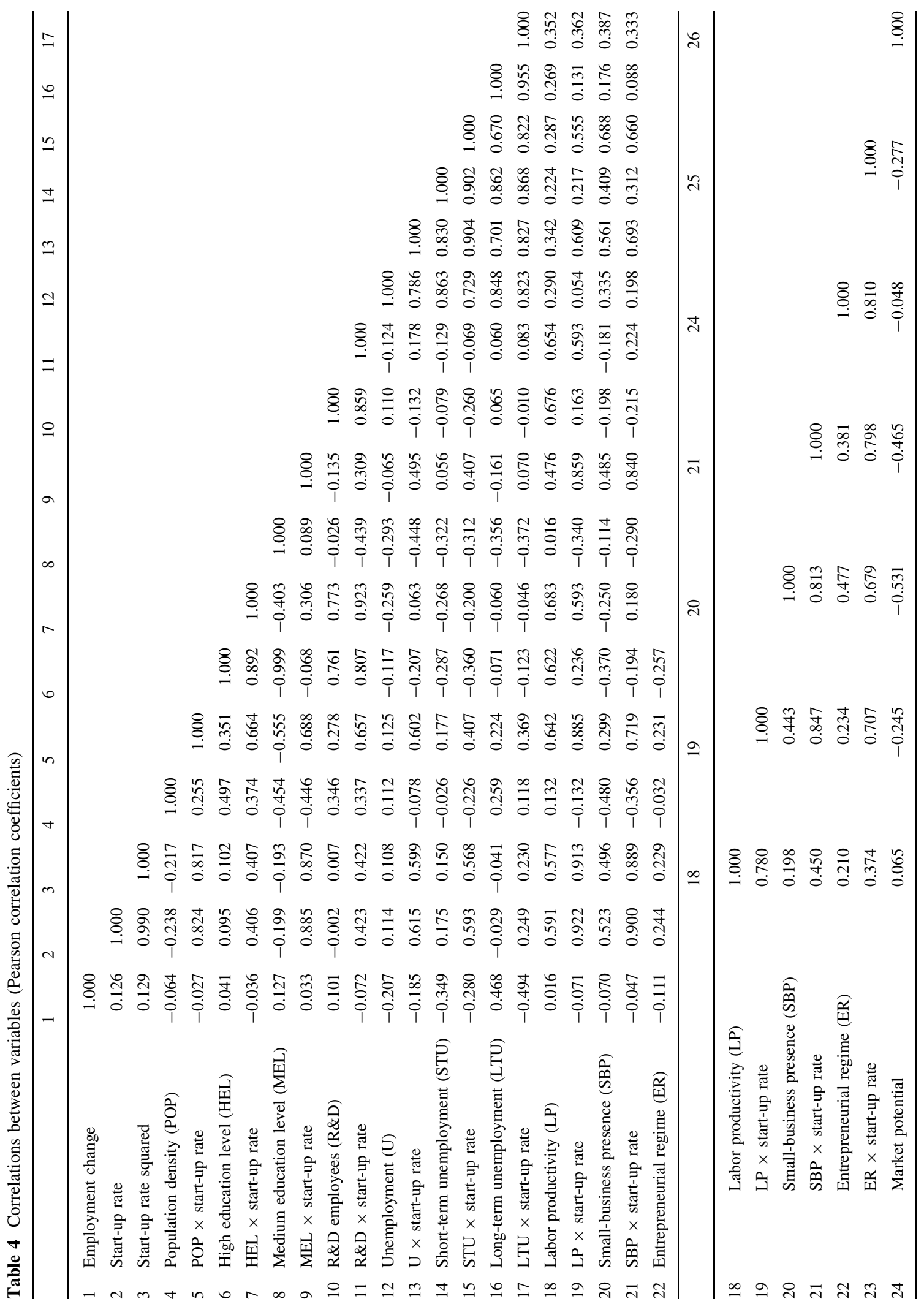




\section{References}

Acs, Z. J., \& Audretsch, D. B. (1987). Innovation, market structure and firm size. Review of Economics and Statistics, 69, 567-575.

Acs, Z. J., \& Mueller, P. (2008). Employment effects of business dynamics: Mice, gazelles and elephants. Small Business Economics, 30, 85-100.

Acs, Z. J., \& Plummer, L. A. (2005). Penetrating the "knowledge filter"' in regional economies. The Annals of Regional Science, 39, 439-456.

Aghion, P., Blundell, R., Griffith, R., Howitt, P., \& Prantl, S. (2009). The effects of entry on incumbent innovation and productivity. Review of Economics and Statistics, 91, 20-32.

Andersson, M., \& Noseleit, F. (this issue). Start-ups and employment dynamics within and across sectors. Small Business Economics. doi:10.1007/s11187-009-9252-0.

Arauzo-Carod, J.-M., Liviano-Solis, D., \& Martin-Bofarull, M. (2008). New business formation and employment growth: Some evidence for the Spanish manufacturing industry. Small Business Economics, 30, 73-84.

Audretsch, D. B. (1995). Innovation and industry evolution. Cambridge: MIT Press.

Audretsch, D. B., Carree, M., van Stel, A., \& Thurik, R. (2002). Impeded industrial restructuring: The growth penalty. Kyklos, 55, 81-98.

Audretsch, D. B., \& Fritsch, M. (2002). Growth regimes over time and space. Regional Studies, 36, 113-124.

Audretsch, D. B., Keilbach, M. C., \& Lehmann, E. E. (2006). Entrepreneurship and economic growth. New York: Oxford University Press.

Bade, F.-J., \& Nerlinger, E. A. (2000). The spatial distribution of new technology-based firms: Empirical results for West Germany. Papers in Regional Science, 79, 155-176.

Baptista, R., Escária, V., \& Madruga, P. (2008). Entrepreneurship, regional development and job creation: The case of Portugal. Small Business Economics, 30, 49-58.

Baptista, R., \& Preto, M. T. (this issue). New firm formation and employment growth: Regional and business dynamics. Small Business Economics. doi:10.1007/s11187-0099254-y.

Boeri, T., \& Cramer, U. (1992). Employment growth, incumbents and entrants-evidence from Germany. International Journal of Industrial Organization, 10, 545-565.

Bosma, N., Stam E., \& Schutjens, V. (this issue). Creative destruction and regional productivity growth: Evidence from the Dutch manufacturing and services industries. Small Business Economics. doi:10.1007/s11187-009-9257-8.

Brambor, T., Clark, W. R., \& Golder, M. (2005). Understanding interaction models: Improving empirical analyses. Political Analyses, 13, 1-20.

Brixy, U., Kohaut, S., \& Schnabel, C. (2007). Do newly founded firms pay lower wages? First evidence from Germany. Small Business Economics, 29, 161-171.

Brixy, U., \& Niese, M. (2006). The determinants of regional differences in new firm formation in Western Germany. In P. Nijkamp, R. L. Moomaw, \& I. Traistaru (Eds.), Entrepreneurship, investment, and spatial dynamics: Lessons and implications for an enlarged EU (pp. 109120). Cheltenham: Elgar.
Carree, M., \& Thurik, R. (2008). The lag structure of the impact of business ownership on economic performance in OECD countries. Small Business Economics, 30, 101110.

Carree, M., van Stel, A., Thurik, R., \& Wennekers, S. (2007). The relationship between economic development and business ownership revisited. Entrepreneurship and Regional Development, 19, 281-291.

Combes, P. (2000). Economic structure and local growth: France, 1984-1993. Journal of Urban Economics, 47, 329-355.

Cooper, A., \& Dunkelberg, W. C. (1987). Entrepreneurial research: Old questions, new answers and methodological issues. American Journal of Small Business, 11, 11-23.

Dejardin, M. (this issue). Linking net entry to regional economic growth. Small Business Economics. doi:10.1007/ s11187-009-9255-x.

Duranton, G., \& Puga, D. (2004). Micro-foundations of urban agglomeration economies. In J. V. Henderson \& J.-F. Thisse (Eds.), Handbook of regional and urban economics (pp. 2063-2117). Amsterdam: Cities and Geography.

Engel, D., \& Metzger, G. (2006). Direct employment effects of new firms. In M. Fritsch \& J. Schmude (Eds.), Entrepreneurship in the region (pp. 75-93). New York: Springer.

Falck, O. (2007). Mayflies and long-distance runners: The effects of new business formation on industry growth. Applied Economics Letters, 14, 919-922.

Federal Office for Building, Regional Planning (Bundesamt für Bauwesen und Raumordnung). (2003). Aktuelle Daten zur Entwicklung der Städte, Kreise und Gemeinden (Vol. 17). Bonn: Federal Office for Building and Regional Planning.

Florida, R. (2005). The rise of the creative class. Revised paperback edition. New York: Basic Books.

Fritsch, M. (2008). How does new business formation affect regional development? Small Business Economics, 30, $1-14$.

Fritsch, M., Brixy, U., \& Falck, O. (2006). The effect of industry, region and time on new business survival-a multi-dimensional analysis. Review of Industrial Organization, 28, 285-306.

Fritsch, M., \& Falck, O. (2007). New business formation by industry over space and time: A multi-dimensional analysis. Regional Studies, 41, 157-172.

Fritsch, M., \& Mueller, P. (2004). The effects of new business formation on regional development over time. Regional Studies, 38, 961-975.

Fritsch, M., \& Mueller, P. (2006). The evolution of regional entrepreneurship and growth regimes. In M. Fritsch \& J. Schmude (Eds.), Entrepreneurship in the region (pp. 225244). New York: Springer.

Fritsch, M., \& Mueller, P. (2008). The effect of new business formation in regional development over time: The case of Germany. Small Business Economics, 30, 15-29.

Fritsch, M., \& Weyh, A. (2006). How large are the direct employment effects of new businesses? - an empirical investigation. Small Business Economics, 27, 245-260.

Glaeser, E. (1998). Are cultures dying? Journal of Economic Perspectives, 12, 139-160.

Glaeser, E. (1999). Learning in cities. Journal of Urban Economics, 46, 254-277. 
Glaeser, E., Kallal, H., Scheinkman, J., \& Shleifer, A. (1992). Growth in cities. Journal of Political Economy, 100, 1126-1152.

Glaeser, E., Scheinkman, J., \& Shleifer, A. (1995). Economic growth in a cross-section of cities. Journal of Monetary Economics, 36, 117-143.

Grupp, H., \& Legler, H. (2000). Hochtechnologie 2000. Karlsruhe: Fraunhofer Institute for Systems and Innovation Research (ISI).

Koster, S. (this issue). Individual foundings and organizational foundings: Their effect on employment growth in the Netherlands. Small Business Economics. doi:10.1007/ s11187-009-9253-z.

Kowalewski, J., \& Niebuhr, A. (2008). Aktuelle Tendenzen der sektoralen und regionalen Beschäftigungsentwicklung, $I A B$ regional 01/2008. Nuremberg: Federal Employment Office.

Kronthaler, F. (2005). Economic capability of East German regions: Results of a cluster analysis. Regional Studies, 39, 739-750.

Lucas, R. (1988). On the mechanics of economic development. Journal of Monetary Economics, 22, 3-42.

Mueller, E., \& Morgan, J. N. (1962). Location decisions of manufacturers. American Economic Review, 52, 204-217.

Mueller, P., van Stel, A., \& Storey, D. J. (2008). The effect of new firm formation on regional development over time: The case of Great Britain. Small Business Economics, 30, 59-71.

Peneder, M. (2002). Industrial structure and aggregate growth. Structural Change and Economic Dynamics, 14, 427-448.

Pesaran, M. H. (2004). General diagnostic tests for cross section dependence in panels. IZA Discussion Papers 1240. Bonn: Institute for the Study of Labor.

Redding, S., \& Sturm, D. (2008). The costs of remoteness: Evidence from German division and reunification. The American Economic Review, 98, 1766-1797.

Romer, P. M. (1986). Increasing returns and long-run growth. Journal of Political Economy, 94, 1002-1037.

Romer, P. M. (1990). Human capital and growth: Theory and evidence. Carnegie-Rochester Conference Series on Public Policy, 32, 251-286.
Saxenian, A. (1994). Regional advantage: Culture and competition in silicon valley and route 128. Cambridge, MA: Harvard University Press.

Schindele, Y., \& Weyh, A. (2010). The direct employment effects of new businesses in Germany revisited-an empirical investigation for 1976-2004. Small Business Economics (forthcoming).

Schroeter, A. (2009). The effect of new business formation on employment - the dominance of density. Jena Economic Research Papers 2009-19. Jena: Friedrich Schiller University and Max Planck Institute for Economics.

Shapiro, J. (2006). Smart cities-quality of life, productivity, and the growth effects of human capital. Review of Economics and Statistics, 88, 324-335.

Simon, C., \& Nardinelli, C. (2002). Human capital and the rise of American cities 1900-1990. Regional Science and Urban Economics, 32, 59-96.

Spengler, A. (2008). The establishment history panel. Schmollers Jahrbuch/Journal of Applied Social Science Studies, 128, 501-509.

Stam, E. (2007). Why butterflies don't leave: Locational behaviour of entrepreneurial firms. Economic Geography, $83,27-50$.

Südekum, J. (2008). Convergence of the skill composition across German regions. Regional Science and Urban Economics, 38, 148-159.

Van Stel, A., \& Storey, D. J. (2004). The link between firm births and job creation: Is there a Upas tree effect? Regional Studies, 38, 893-909.

Van Stel, A., \& Suddle, K. (2008). The impact of new firm formation on regional development in The Netherlands. Small Business Economics, 30, 31-47.

Weyh, A. (2006). What characterizes successful start-up cohorts? In M. Fritsch \& J. Schmude (Eds.), Entrepreneurship in the region (pp. 61-74). New York: Springer.

Winter, S. G. (1984). Schumpeterian competition in alternative technological regimes. Journal of Economic Behavior and Organization, 5, 287-320. 